\title{
Research on current situations of geriatric nursing education
}

\author{
Yujin Liu, Min Zhang ${ }^{\text {a }}$, Wenjing Sun, Fengge Dong, Xiufeng Zhao and Bing Yu \\ Welfare College of Nursing of College of Humanities \& Northeast Normal University, 130117, Changchun, China
}

\begin{abstract}
The population aging is accelerating and the aging population is growing in China. Although the geriatric nursing education has been developed for more than 20 years, geriatric nursing professionals are still insufficient and the geriatric nursing education is facing various challenges under the new situation. This paper primarily describes the developmental history and the related concepts of geriatric nursing education, and analyzes the personnel training modes and routes of geriatric nursing education, and its problems, in order to provide the basis for the reform of geriatric nursing education. The development of geriatric nursing needs a large number of outstanding nursing personnel, and the cultivation of geriatric nursing professionals depends on the development of geriatric nursing and the improvement of the teaching quality of geriatric nursing education. Front-line educators working on geriatric nursing should be committed to reforming the geriatric nursing teaching, improving the teaching quality and cultivating the high-quality nursing personnel suitable for conditions of the elderly in China.
\end{abstract}

\section{Introduction}

Geriatric nursing was determined as an independent specialty internationally in 1900 and geriatric nursing education has been developed for more than 20 years in China, but the geriatric nursing personnel is still insufficient, indicating that the work of geriatric nursing is facing challenges under the new situation [1] and there is still much to do in the improvement of geriatric nursing education [2]. Moreover, nurses can and should play a unique role in care of the elderly by nursing education, research and practice, which can improve not only the quality of eldercare, but also the quality of elderly life that is more important. This paper aims to understand the progress in the research on China's elderly nursing education to provide a basis for the future research on geriatric nursing education.

\section{Concepts Related to Geriatric Nursing Education}

Geriatric nursing is a subject to research, diagnose and treat the responses to their own present and potential health problems in elderly. Geriatric nursing was originated from theories of already existing subjects such as nursing, sociology, biology, psychology, health policy and other disciplines. Geriatric

${ }^{a}$ Corresponding author: Zhang Min, E-mail:1874751233@qq.com

Higher Education Research Key Project (2014.11.10) sponsored by Department of Education, Jilin Province. 
nursing stresses to maintain and promote health, prevent and control disabilities resulting from acute and chronic diseases in elderly to develop their daily living abilities, make their body functions in the best state, and keep their living life with dignity and comfort until they leave this world [3]. Nursing education refers to activities to cultivate the professionals with a wide and deep knowledge in medicine, humanities and nursing, and able to serve for health services for the nursing discipline [4]. Geriatric nursing education is a social activity to cultivate the geriatric nursing professionals based on the social need.

\section{Development of Geriatric Nursing Education}

Early 20th century, the development of geriatric nursing education was slow in China. After the 1990s, the development of nursing higher education was accelerated and geriatric nursing were gradually determined as a course in many colleges and universities, but just as an elective professional course [5]. Only after 1998, was geriatric nursing established as a required course in a few higher nursing schools, but it was not popularized in our country, and geriatric nursing as an undergraduate teaching material was published in December 2000 [6]. Since then, monographs, textbooks, popular science books related to geriatric nursing were published in succession; works and papers about geriatric nursing were published in various related magazines, showing the starting of research on geriatric nursing. So far, there have been few nursing schools that are preparing to establish geriatric nursing specialty for nursing undergraduates and the research field of geriatric nursing has been also set up in the nursing graduate education. In addition, the domestic and international academic exchange in geriatric nursing has been gradually developed, and a long-term research partnership with counterparts of foreign countries in geriatric nursing has been established in some institutions.

\section{Geriatric Nursing Education Status}

\subsection{Establishment of nursing specialty to cultivate geriatric nursing professionals}

Documents showed that the "establishment of the nursing specialty to cultivate nursing professionals" was proposed in 2009, and has been proposed by many scholars since 2011. It is estimated that the elderly population will reach a maximum by 2051 in China, and after that, the elderly population will been maintained at 3 to 4 million and the total population aged 65 or older increased from $7 \%$ to $14 \%$. The increase in aging population requires for new services in geriatric nursing institutions, such as older community service centers, rehabilitation agencies, apartments for the elderly and nursing homes, in which most work needs a large number of nurses to accomplish. However, the education for geriatric nursing is limited at all levels, even in the United States, certified geriatric nursing nurses is less than $1 \%$ of 2.5 million registered nurses. The shortage of geriatric nursing nurses and geriatric nursing specialist nurses, and the lack of funds for the long-term care for the elderly, result in the difficult to guarantee the nursing quality in home for the aged and at home. Currently the number of nursing staff is insufficient, and there are a few of nurses engaged in geriatric nursing with a low education, who have not received a systemic education in geriatric nursing, leading to the irrational structure and the lack of their professional knowledge; professional research staff with master or doctor degree is even more inadequate. Therefore, the professional in geriatric nursing is scarcer, [7] so that it is urgent to develop a geriatric nursing specialty in colleges and universities to cultivate the personnel for geriatric nursing. To strengthen the education of geriatric nursing to train more professionals for geriatric nursing is one of urgent problems currently to be considered and solved by the higher medical and nursing education institutions [8]. In 2013, Ningbo Health College has taken the lead in the establishment of geriatric nursing specialty. The establishment of geriatric nursing specialty may play a crucial role in the culture of geriatric nursing personnel, but the training of advanced geriatric nursing personnel requires for not only the establishment of geriatric nursing specialty but also the education of doctor graduates in medical colleges and universities to cultivate 
high-level geriatric nursing professionals with highly educated degree. In addition, the continuing education for in-service nurses should be vigorously carried out, such as teaching by correspondence, Self-learning, and seminars or online distance education, to organize clinical in-service and community nurses for further study and cultivate social practical geriatric nursing personnel to meet the needs of an aging society [7].

\subsection{Emphasis on the application of teaching methods and modes to promote the teaching reform}

According to the literature statistics, studies on geriatric nursing teaching methods account for $29.74 \%$, indicating that China attaches great importance to the application of teaching methods for geriatric nursing education to improve the teaching quality of geriatric nursing. Studies have shown that the application of modular teaching [9], contract learning [10], case-based teaching and situation teaching [11], the real experience teaching [12], think aloud [13], case discussion-based salon [14], developmental case-based discussion [15] and theory and practice integration [16] can reflect the combination of theory and practice, improve the quality of geriatric nursing teaching, and make for the cultivation of new geriatric nursing professionals suitable for the needs of social development. In addition, the three dimensions of attribution theory, source of cause, stability and controllability, are integrated into the education of geriatric nursing, in which the students are trained in the adaptive attribution for improving their interest in the learning. The attribution training could guide the success in the learning of geriatric nursing to the internal attribution of their efforts and abilities, and the failure to the controllable attribution of their inadequate efforts and wrong learning way, to improve their comprehensive abilities [17]. The application of constructivist learning theory [18] may make students not passively receive knowledge but actively construct knowledge in the learning process, more interested and motivated in the learning of geriatric nursing, and learn something critically, which may bring about a revolution in the teaching or learning. Studies have suggested that the nursing education should be reformed to adapt to the needs of the future society, and more attention should be paid to the specialized training for geriatric nursing staff [19], and the six-in-one training model for nursing personnel should be emphasized to connect the quality education, expertise, teaching content, teaching team, experimental and practical training, and examination and assessment to the need of job [20], combine the theory with the practice, and improve students' presentation and communication skills, analytical and problem-solving skills, coordination and cooperation abilities, and innovative abilities [21].

\subsection{Active exploration on effective ways for the nurses' in-service training and continuing education}

Nurses are thinkers, designers, commanders and providers of geriatric nursing, and the improvement of the health and living standards of the elderly relies on the popularity, improvement and clinical utilization of geriatric nursing knowledge [22]. The existing clinical nurses are the main force in geriatric nursing facilities and the strengthening of clinical nurses' in-service training and continuing education is the key to improve the geriatric nursing education. The main way of continuing education in geriatric nursing is still the traditional face-to-face teaching, such as various classes for further studies, workshops, academic seminars, academic conferences, symposia, and degree courses [23]. It is recommended that the continuing education of clinical nurses should be carried by case-based teaching, sim-man education system and online knowledge base [24]. The teaching of vocational education should be carefully designed and reformed based on the characteristics of top-up students and in terms of the teaching contents, teaching methods and examination forms to achieve better teaching results [25]. The main measures to deal with it should be a diversified vocational education, including the national health education, the vocational education of nursing workers at nursing institutions for the aged, the job-transfer training of clinical nurses, and the setting-up of geriatric nursing specialty and curriculum, and it is necessary to cultivate the civil awareness of pension and 
provision for old age, and to bring up a pension team with strong professional skills in geriatric nursing; simultaneously to speed up the training of advanced geriatric nursing staff and managers [26].

\subsection{Close attention paid to the geriatric nursing education abroad}

In the process of active exploration on the geriatric nursing education, a close attention should be paid to the progress status in it in foreign countries to actively learn from their related experiences. Studies by Wang Zhangan [27] have shown that a geriatric nursing personnel should have the following capabilities: (1)core competencies to provide a high-quality care for the elderly and their families; (2)geriatric nursing capacities and suggestions on course contents and teaching strategies corresponding to " High Education Standards of Nursing Profession" (1998 revision); (3)core competencies, course contents and teaching strategies prescribed in the curriculum setting up; (4) resources/documents of the implementation of geriatric nursing course contents and teaching strategies. The continuing education in the United States provides opportunities for nurses to facilitate their improvement in geriatric nursing knowledge and skills, primarily including web-based geriatric nursing courses, distance learning and professional website [28]. The geriatric nursing education in Australia can be basically divided into four levels, secondary, vocational, undergraduate and master, nursing graduates at each level perform their own duties, and the main nursing staff is from the secondary specialized vocational education. The continuing education of geriatric nursing staff is completed mainly by their service units, and supervised and administered by Australian Board of Nurses. In Australia nursing homes, for example, its geriatric nursing continuing education system consists of three parts, orientation, in-service training and job training out of hospitals. Lin Jie [29] believed that the advanced classifying education system and the sophisticated continuing education system of geriatric nursing in Australia should be worth our learning. The main body of geriatric nursing legislation in Japan, improved geriatric nursing management network in Sweden and threelevel geriatric nursing education in German (secondary, specialist training, college undergraduate) is their secondary vocational training education [30], primarily to train geriatric nursing nurses and nurse assistants [31], which is worthy of our study. Studies described above indicate that the geriatric nursing education in our country should be developed by working out a perfect law and system, establishing an improved management network and service, developing a pension mode with diversification and differentiation, and paying more attention to the diversified geriatric nursing education based on the vocational education to explore a mode suitable for the current development of geriatric nursing.

\section{Currently Existing Problems in Geriatric Nursing Education}

\subsection{Relative lack of research on the geriatric nursing education}

Geriatrics and geriatric nursing are relatively young sciences. Despite a sharp increase in demand for geriatric nursing research, but most focus on biomedicine, little attention is paid to geriatric nursing. Due to the relative lack of research on the practice of geriatric nursing education, more nurses should work on the research on geriatric nursing and apply their findings into the practice. In addition, studies have showed that the deep study on geriatric nursing education systems is still lack in colleges and universities [26]. Nurses must play an important role in the care of the elderly through the education, advanced practice and impetus of policies. Therefore, more undergraduate and graduate courses are needed to promote the education of geriatric nursing theory and its advanced practice, and at the same time the nursing research related to Chinese culture and needs of elderly should be carried out.

\subsection{Lack of systematic geriatric nursing course}

Most importance has been attached to the training of general nurses in the nursing education, and the 
specialist nursing system and specialist nursing education mode have been not developed yet in China. Geriatric nursing is not only a multi-disciplinary course, but also a practical service course. Geriatric nursing course was not opened in several school of nursing until 1998, "geriatric nursing" a planning teaching materials of Ministry of Health of People's Republic of China, was officially published in December 2000, which is a common teaching materials for both undergraduates and junior college students [32]. Currently, geriatric nursing course is taught primarily in a way of theoretical teaching and as a selective course with less contents and teaching hours compared to the other courses. The practical learning is relatively insufficient, since there is no systematic practical course of geriatric nursing in colleges and universities, and sites for the geriatric nursing internship are mainly hospitals, showing the lack of opportunities for the students to practice in different nursing-care places; all the training courses are integrated into the teaching of fundamental nursing. In this way, the students can only superficially understand the knowledge of geriatric nursing, can not fully understand the knowledge and skills necessary for geriatric nursing [24], and can not meet the actual requirements of geriatric nursing. In addition, there are other problems to be solved in geriatric nursing education, such as the students' poor willingness to working on geriatric nursing, the lack of geriatric nursing knowledge in clinical nurses, the nurses' poor awareness on the service for elderly nursing and health care [33], and the lack of geriatric nursing teachers. All the problems existing in geriatric nursing education require nurses continuously to explore effective solutions to solve them.

\section{Summary}

The development of geriatric nursing needs a large number of outstanding nursing personnel, and the cultivation of geriatric nursing professionals depends on the development of geriatric nursing and the improvement of the teaching quality of geriatric nursing education. Front-line educators working on geriatric nursing should be committed to reforming the geriatric nursing teaching, improving the teaching quality and cultivating the high-quality nursing personnel suitable for conditions of the elderly in China, so as to contribute to the improvement and the development of geriatric nursing.

\section{References}

1. Hu yan, Wang Yan. Practice on setting up the elderly care specialty in undergraduate nursing education. Chinese Nursing Management,13,2(2013).

2. Liu Ning, Guo Guifang. The status of demand conditions in elderly care in China and thinking on the cultivation of geriatric nursing personnel. Chinese Nursing Management,11,4(2011).

3. Hua Qianzhen. Geriatric Nursing. The 2nd Edition. Beijing: People's Medical Publishing House(2007) .

4. Zheng Xiuxia. Introduction to nursing education. Beijing: Peking University Medical Press(2011).

5. Gao Wenrong, Li Chunying, Li Caifu. The status and prospect of geriatric nursing education in China. Science and Technology Information, 36(2011).

6. Wang Ling. Development history of geriatric nursing subject and thinking on it.Chinese Nursing Management, 7, 4(2007).

7. Sun Shuiying, Zeng Hui, Zhang Liping. Population aging and nursing present conditions and countermeasures in China. Journal of Nursing Science, 21, 21(2006).

8. Yu Changmei. Requirements of geriatric nursing and discussion on the setting up of geriatric nursing courses, Today Nurse, 6(2002).

9. Xiao Xinli, Yang Xiaobin. Application of module-instruction in the teaching of geriatric nursing. Journal of Nursing Science,23,14 (2008).

10. Yang Zhilan, Yang Jianping, Wu Xiaohong, et al. Practice of contract learning in teaching of geriatric nursing. Journal of Nursing Science, 24, 23(2009).

11. Sun Mengxia, Jiang Na, Liao Guixiang. Application of case teaching and situation teaching method in teaching of "geriatric nursing". Chinese Nursing Research, 25,8B(2011).

12. Wang Ling, Xiao Shuqin. The application of experiential teaching in geriatric nursing for nursing 
undergraduate students. Chinese Nursing Management,13 , 2(2013).

13. Zou Yadong, Guo Mingxian, Cui Yan, et al. Application of think aloud discussion teaching method in teaching of "elderly nursing". Chinese Nursing Research,27,7B (2013).

14. Xie Xiaoyan, Li Jiayi, Zhang Chi, et al. Application of case-based discussion salon in elderly patients nursing for backbone training. Nursing Journal of People's Liberation Army,30, 9(2013).

15. Xiao Lily, Dong Xia, Shen Jun, Liu Hui. Application of developmental case-based discussion in continuing education of geriatric nursing in China. Chinese Journal of Gerontology, 32, 23(2012).

16. Liu Wei, Yang Lvqing, Ding Ping. Application of theory and practice integration. Journal of Nursing, 20,9B(2013).

17. Liu Wei. Application of attribution theory in teaching of geriatric nursing. Nursing Practice and Research,5,8(2008).

18. Guo Xiaoyan, Zhang Feng. The application of constructivism learning theory in geriatric nursing. China Higher Medical Education,5(2012).

19. Yuan Xiaoling, Kang Youle, Shi Hongni. Thinking on nursing demands of aged people and nursing education reform. Chinese Nursing Research,19,10A(2005).

20. Li Ruzhu, Jiang Yuehua, Zeng Xiaoying. Exploration on nursing personnel cultivation model of "six-in one" and its practice. Chinese Journal of Nursing Education,6,12 (2009).

21. Gao Jingquan. Evaluation on effect of carrying out community practice in geriatric nursing teavhing. Chinese Nursing Research, 23, 5(2009).

22. Xu Xiulan. Population aging and elderly nursing development. Tianjin Journal of Nursing,9, 5(2001).

23. Liu Yue. Development and status of continuing medical education in China. Chinese Journal of Primary Medicine and Pharmacy,8,1(2001).

24. Liu Mengjie, Wu Youfeng, Zhao Jijun. Overview and propositions of carrying out geriatric nursing continuing education for clinical nurses. Chinese Nursing Research,24, 9(2010).

25. Zeng Lifang. Exploration on reform of geriatric nursing teaching for junior undergraduate students. Health Vocational Education,23,15(2005).

26. Chen Siqing. Research on diversified vocational of aged care. Journal of Nursing, 18, 6B(2011).

27. Wang Zhangan, Zheng Honglai. Talking on the core competency standards and teaching strategies of geriatric nursing in nursing undergraduate education in the United States. Chinese Nursing Research,25, 11(2011).

28. Liu Xueqin, Li Li. The development of gerontological nursing in America: implications for China. Chinese Journal of Nursing,4, 12(2005).

29. Lin Jie. The present condition and the enlightenment of elderly nursing education in Australia. Nursing Practice and Research, 9,21(2012).

30. Liu Xiaomin. Geriatric nursing in Geman. Chinese Journal of Nursing, 20013, 6(7): 560-561.

31. Peng Landi. Aged care experience in developed countries and prospect of our aged care in China. Chinese Nursing Research,25,5A (2011).

32. Wang Jing, He Guoping. Problems of nursing human resources for elderly patients in China and countermeasures. Journal of Nursing Science, 25,23(2010).

33. Tang Fengping. Strengthening of elderly care awareness in teaching of geriatric nursing, Modern Nursing,12, 6(2006). 